\title{
Entre a memória e a História: o Cebrap e os 50 anos do Golpe Civil-Militar
}

\author{
Between memory and History: Cebrap and the 50 years of the civil-military Coup \\ Entre la mémoire et l'Histoire: le Cebrap et les 50 ans de le Coup civil-militaire \\ Entre la memoria y la Historia: el Cebrap y los 50 años del Golpe cívico-militar
}

Karla Carloni[1]

\author{
ALONSO, Ângela. DOLHNIKOFF, Miriam. (orgs.). 1964: do golpe à democracia. São \\ Paulo: Hedra, 2015. 418 p.
}

E m 2014, como é sabido, o Golpe Civil-Militar completou 50 anos e um número grande de eventos debateu os 21 anos em que o Brasil viveu $\checkmark$ sob a tutela militar. Diferentes áreas do conhecimento produziram significativas reflexões. Na esteira de rememorações, o Centro Brasileiro de Análise de Planejamento (Cebrap) promoveu, em março do mesmo ano, o seminário "1964: do golpe à democracia". O encontro deu origem à publicação de livro de igual nome, lançado em 2015 e organizado por Ângela Alonso e Miriam Dolhnikoff. Reunindo doze artigos e oito depoimentos, o volumoso livro promove de maneira original o diálogo entre trabalhos clássicos e recentes desenvolvidos por integrantes do Centro e especialistas de outras instituições, além da memória de destacados personagens que passaram pelo Cebrap. Dois grandes blocos compõem o volume, o primeiro trata múltiplos aspectos da crise política de 1964 e do Regime Militar e o segundo aborda por diferentes ângulos o processo de redemocratização. ${ }^{2}$

Detentor de respeitável produção acadêmica, o Cebrap foi criado em 1969 por um grupo multidisciplinar de professores e pesquisadores ligados à Universidade de São Paulo, e, em sua maioria, afastados da universidade pelo regime. Consolidado como um centro de pesquisa em humanidades dedicado à análise de questões nacionais e à intervenção na realidade brasileira, seus pesquisadores se propuseram à compreensão da dinâmica política, social, econômica e cultural da sociedade. Atualmente o Centro abriga grupos

Resenha recebida em 14 de agosto de 2015 e aprovada para publicação em 28 de outubro de 2015

[1]Professora do Departamento de História da Universidade Federal Fluminense (UFF) - Niterói (RJ) - Brasil. E-mail: karlacarloni@gmail.com

${ }^{2} \mathrm{O}$ volume faz parte de projeto mais amplo do Cebrap. Em 2014 foram publicados os volumes: De Médici a Geisel e De Figueiredo à Nova República, reunindo artigos lançados nas revistas do centro durante o Regime Militar e a redemocratização. 
que pesquisam desde temas clássicos, como democracia e cidadania, a assuntos bastante atuais, como meio ambiente e cultura digital. ${ }^{3}$

Após introdução escrita pelas organizadoras, a primeira sessão do livro é aberta com texto de Argelina Figueiredo. Em "O Brasil na encruzilhada" a cientista política retoma seu estudo já clássico a respeito da crise que levou ao golpe e lança como questão o porquê de não ter sido possível durante o governo de João Goulart uma solução que combinasse democracia com a realização das reformas de base. Argelina rechaça explicações estruturais ou determinismos políticos e econômicos e defende que para a compreensão da crise de 1964 é fundamental a análise do comportamento e das estratégias dos atores políticos em cada conjuntura. As alternativas possíveis e as condições de realização de acordos que permitissem a governabilidade são apontados como aspectos igualmente importantes. Para a autora, a polarização radicalizada das forças políticas teria sido a grande responsável pela incapacidade de formulação de um compromisso político que viabilizasse uma solução aceitável para a crise, levando, consequentemente, as instituições democráticas à ruína. Às vésperas do golpe, o cenário era dual e irreconciliável, as esquerdas de um lado e, do outro, a coalisão golpista reunindo amplos setores sociais identificados com o conservadorismo. $\mathrm{O}$ caminho trilhado pelos atores políticos teria levado ao colapso do regime democrático representativo.

\section{Reunindo doze artigos e oito depoimentos, o volumoso livro promove de maneira original o diálogo entre trabalhos clássicos e recentes}

No capítulo seguinte, "O golpe faz 50 anos", Jorge Ferreira retoma a interpretação de Argelina Figueiredo e apresenta reflexões que ajudam na compreensão da dinâmica da crise de 1964. Recusando análises teleológicas que apontam para a inevitabilidade do Golpe, o autor anuncia ser fundamental uma análise processual, como também defende a necessidade de compreensão das opções dos diferentes atores políticos e das possibilidades na conjuntura em questão. O caminho trilhado não estaria predeterminado desde de 1961. Várias oportunidades de acordos e compromissos entre esquerdas e direitas se abriram no sentido de viabilizar a continuidade do processo democrático com a efetivação das reformas, inclusive a reforma agrária. Porém, uma a uma fracassou, o que selou o destino do regime inaugurado em 1964. Nesse sentido, defende o historiador, cabe destacar que o golpe foi uma articulação dos grupos políticos de direita apoiados pelo centro contra o governo Goulart e sua opção de aliar-se às esquerdas no início de 1964.

${ }^{3}$ Dados retirados da homepage: <http://cebrap.org.br/v3/index.php?r=institucionais/index.> Acesso em 27 ago. 2015. 
José Arthur Giannotti em "Brevíssimas considerações sobre o Estado e a política” apresenta um misto entre a sua própria trajetória política e intelectual às vésperas do golpe e uma reflexão a respeito da democracia brasileira na atualidade. Alertando sobre o risco da política contemporânea brasileira constituir uma "farsa democrática", em poucas páginas o filósofo denuncia a diluição da contrariedade em nome de grandes alianças como marca da política nacional e defende a importância da sobrevivência de grupos contrários para o aprimoramento da democracia.

Nos três artigos que finalizam a primeira parte, análises de distintas áreas da cultura reforçam a necessidade de uma revisão historiográfica e da crítica às memórias cristalizadas. Por diferentes caminhos os autores demonstram as debilidades interpretativas das leituras que definem a experiência autoritária a partir da aposição repressão versus modernização, e propõem a elaboração de uma reflexão mais atenta às complexidades das relações dos diferentes grupos sociais com o processo de modernização autoritária e à diversidade no interior das esquerdas.

\section{Análises de distintas áreas da cultura reforçam a necessidade de uma revisão historiográfica e da crítica às memórias cristalizadas}

Rodrigo Motta, em "A política universitária da ditadura e as ciências sociais", apresenta resultados de pesquisas a respeito do crescimento das universidades durante o Regime Militar. O historiador rejeita interpretações que observam unicamente a repressão nos meios acadêmicos e a tentativa de cooptação de seus intelectuais. No caso das Ciências Sociais, campo caracterizado por forte identidade de esquerda, o autor detecta que, embora não fosse alvo direto das políticas de modernização, o setor conheceu o florescimento de suas pesquisas ao receber importantes incentivos de instituições ligadas ao capital privado internacional e de órgãos públicos. O próprio Cebrap, que reunia intelectuais perseguidos, foi beneficiado pelo apoio financeiro da norte-americana Fundação Ford. A constatação desse panorama positivo para as Ciências Sociais, sobretudo na década de 1970, afirma o autor, exige novos estudos que aprofundem de forma mais refinada a compreensão da complexa relação do regime com o meio acadêmico.

Em "História e memória da resistência cultural durante o Regime Militar brasileiro", Marcos Napolitano, aponta a necessidade de um reposicionamento de questões clássicas relacionadas ao tema da experiência cultural das esquerdas. Como, por exemplo, o que define a arte engajada como uma produção voltada apenas para o consumo da classe média ou o que interpreta que a massificação da cultura, via mercado, teria posto fim na arte politizada de esquerda. O historiador lança a proposta de compreensão efetiva da complexa 
relação entre a arte engajada, entendida como protagonista, o mercado e a Ditadura Militar. Longe de serem opostos, repressão e mecenato conviveram e a lógica dessa união não se limita à tentativa de cooptação do artista por parte do regime. Napolitano chama o historiador aos desafios da pesquisa e defende a crítica das memórias e interpretações simplificadoras e pouco elucidativas a respeito das lutas culturais do período.

Por fim, Ismail Xavier encerra o primeiro bloco com "O momento do golpe, as primeiras reações e percurso do cinema de oposição no período da ditadura" no qual identifica a elaboração de diferentes estratégias por parte dos cineastas no processo de resistência, incluindo o diálogo com diversos espaços, grupos sociais e opções estéticas. Distante de se constituir como simples braço cultural das organizações de esquerda, o cinema, na tentativa de explicar a realidade brasileira, se constituiu em espaço de diversidade e tensões. Semelhante a Napolitano, o autor ressalta a dificuldade de se equacionar a relação entre arte engajada, a Ditadura Militar e o mercado. A aparente contradição entre a censura e o incentivo do regime à produção cinematográfica nacional traz um elemento a mais para a já complexa dinâmica. A história da Embrafilme, por exemplo, não estaria isenta de contradições, mas pode ser definida como expressão de um nacionalismo cultural ilustrado que deve ser melhor compreendido.

\section{Por diferentes caminhos os autores demonstram as debilidades interpretativas das leituras que definem a experiência autoritária a partir da aposição repressão versus modernização}

No conjunto de depoimentos tanto da primeira quanto da segunda parte do livro está o registro de memórias e análises de personagens relacionados à luta em defesa dos Direitos Humanos, além de destacados integrantes ou ex-integrantes do Cebrap. Recheadas de leituras políticas e sensibilidades, as memórias registradas possuem, em maior ou menor grau, pontos em comum. Destacam-se os relatos sobre a juventude e militância política; as carreiras interrompidas pela repressão; a definição do Cebrap como uma forma de resistência; além de uma reavaliação da atuação política das esquerdas e os diferentes caminhos trilhados pelos referidos atores sociais após 1985.

O primeiro depoimento é do ex-presidente da República e um dos fundadores do Cebrap, Fernando Henrique Cardoso. Partindo de suas memórias, o sociólogo propõe uma interpretação para o golpe calcada em uma análise estrutural da economia e da sociedade brasileiras e na correlação entre três processos: a elaboração de uma ideologia interventora por parte dos militares; o advento da Guerra Fria; e a fragilidade da democracia brasileira.

Francisco de Oliveira é o segundo depoente e suas memórias revelam o impacto do golpe no Recife, que resultou na sua prisão e na do então governador 
Miguel Arraes. O sociólogo destaca como estudos feitos pelo grupo envolvido com o Cebrap foram apropriados pelo partido Movimento Democrático Brasileiro (MDB) e como integrantes participaram ativamente da fundação do Partido dos Trabalhadores (PT). Contudo, sobressai a crítica do intelectual às expectativas das esquerdas no contexto da redemocratização. Para Oliveira teria sido uma grande ilusão achar que o processo seria levado a cabo pela classe operária, quando na realidade foram as classes médias que exerceram o papel central, o que implica repensar a análise da sociedade brasileira e as estratégias políticas atuais no âmbito das esquerdas.

O depoimento do economista Paul Singer é de todos o mais longo. Os primeiros passos da militância política no movimento sionista de esquerda e no partido socialista foram importantes componentes para o amadurecimento do jovem filho de refugiados do nazismo. Já como professor com carreira ascendente na Universidade de São Paulo (USP) teve a sua trajetória interrompida pela perseguição política e pela prisão. Reflexões polêmicas sobre a origem da repressão relacionada ao AI5 e a anistia aos militares estão no depoimento que revela uma descrença nos atuais partidos políticos brasileiros.

Os três últimos depoimentos da primeira parte do volume relatam principalmente experiências relacionadas ao "pesadelo do golpe". A demógrafa Elza Berquó teve a sua trajetória acadêmica na USP e os estudos sobre população interrompidos pela repressão, tornando-se o Cebrap meio de sobrevivência em cenário tão adverso. Já o depoimento de Isaura Botelho é o mais dramático. Resgata as memórias da intensa militância na Ação Popular, as dores da experiência de perder o marido para a repressão e a necessidade de reconstruir a vida. A trajetória da depoente é marcada pela angústia e a dolorida memória ganha possíveis significados nos lenços bordados à mão que reúnem pedacinhos de sua própria história. Por fim, José Carlos Dias, que se destacou durante o regime por ter dado assistência jurídica a presos processados e torturados sensibiliza o leitor relatando a sua intensa atuação junto àjustiça militar. A memória, que conjuga a sensação de medo à dolorosa experiência da defesa de presos políticos sabidamente mortos, demonstra a dura realidade, ainda não totalmente esclarecida, da repressão militar.

Dedicada à compreensão da Nova República, a segunda parte do volume é aberta pelo texto "Notas sobre a (re)democratização" de Brasílio Sallum Júnior. Retomando a forma de raciocínio apresentada, sobretudo nos artigos de Argelina Figueiredo e Jorge Ferreira, o sociólogo defende o processo de redemocratização como evento controverso que deve ser compreendido a partir de um contexto de crise e das opções dos atores políticos envolvidos, destacando-se a luta das oposições. Embora o fracasso dos planos de liberalização conservadora e de expansão econômica do governo Geisel tivessem composto uma conjuntura que, associada à derrota do governo nas eleições de 1982, abriu espaço para ampliação da atuação da oposição. O que estava realmente em colapso, sugere o sociólogo, não era o regime, mas o próprio 
modelo de Estado nacional-desenvolvimentista erigido desde os anos 1930 e caracterizado pelo intervencionismo econômico e social.

Tal como Gianotti, Marcos Nobre em "Conservadorismo em chave democrática. A redemocratização brasileira, 1979-2013" identifica o atual artifício das grandes alianças políticas como um verdadeiro bloqueio ao aprofundamento do processo democrático. A unidade forçada das oposições durante a transição, defende o filósofo, teria se transformado em princípio ideológico e seria a gênese do atual comportamento conservador dos atores políticos que, em nome da governabilidade, apostam na formação de "superblocos" que diluem os debates e as disputas de projetos.

Em mais um artigo que rejeita teses deterministas, Fernando Limongi analisa o padrão de comportamento da relação entre os poderes Executivo e Legislativo na Nova República. "As bases institucionais da democracia no Brasil" retoma interpretação já clássica elaborada pelo autor e Argelina Figueiredo que contraria as primeiras leituras da atual Constituição marcadas pelo pessimismo. Ao estabelecer o reforço do poder Legislativo da Presidência da República, a carta de 1988 proporciona significativa margem de governabilidade para o Executivo, argumenta o cientista político. Assim, diferentemente da Constituição de 1946, caracterizada pela "indisciplina dos partidos", a nova Constituição não estaria marcada por um "mal de origem". Se é para falar de continuidades, elucida Limongi, faz mais sentido ponderar a respeito da manutenção do processo decisório no Executivo, característica herdada do Regime Militar.

Contrariando o senso comum, Maria Hermínia de Tavares em "A experiência democrática recente. Resultados e percepções", aponta os avanços da democracia brasileira a partir de 1985 . A cientista política apresenta um descompasso desafiador: os resultados alcançados pela democracia e a avaliação negativa das pesquisas de opinião pública. Para a autora, a atual descrença nos partidos e no Congresso seria sintoma de um fenômeno mais amplo presente em outros países ocidentais que é o desprezo pelo regime democrático representativo, fato que, associado às oposições desleais que desacreditam na democracia quando não obtêm vitórias eleitorais, cria desafios à manutenção do próprio regime.

O ciclo de análises sobre o funcionamento do regime democrático brasileiro e da atual conjuntura política se encerra com "Preparação à política. Infraestrutura e conflito na sociedade contemporânea" de Wanderley Guilherme dos Santos. O cientista político define a nova realidade que associa a complexa divisão social do trabalho ao alto grau de organização da sociedade civil em instituições representativas favorecidas pela revolução digital. O cenário é crítico, alerta o autor, há o transbordamento da participação política para além do Parlamento agregada à desmoralização e desprestígio das instituições democráticas por conta das atuações tanto das direitas quanto das esquerdas.

O último artigo do volume celebra de forma crítica um dos mais importantes e recentes passos no processo de aprofundamento do regime 
democrático e compreensão dos impactos políticos e sociais da Ditadura Militar. Em "Justiça de transição e Comissão da Verdade. Vozes das vítimas" GlendaMezarobba apresenta pertinentes reflexões a respeito da noção de justiça de transição; do direito à verdade e à reparação por parte das vítimas; e os limites e contradições da Comissão Nacional da Verdade (CNV).

Por fim, os dois últimos depoimentos são de Paulo Sérgio Pinheiro e Paulo Vannuchi que apresentam reflexões a respeito da complexidade da transição democrática. Membro da CNV, Pinheiro relembra sua trajetória de militância política e sua atuação profissional, trazendo dados para a compreensão das graves heranças do período militar. Já Vannuchi, ex-ministro dos Direitos Humanos, relata sua experiência na militância, os tortuosos cinco anos de prisão e a luta em defesa da justiça de transição.

Os depoimentos presentes no volume contribuem não só para a memória do Cebrap, mas igualmente para a reflexão sobre a complexidade da crise política de 1964, da Ditadura Militar, do processo de redemocratização e, sobretudo, da trajetória de uma destacada geração de intelectuais e atores políticos que atuaram por diferentes caminhos em busca do aprofundamento da democracia brasileira.

Ao analisar sob variados ângulos meio século da história nacional, o livro rejeita leituras deterministas e destaca a importância da compreensão das conjunturas e das opções dos diferentes atores coletivos. Igualmente contraria o pessimismo ao defender que, apesar das contradições e deficiências, importantes avanços democráticos ocorreram após 1985 o que, por sua vez, não descarta a urgência da superação do "entulho autoritário" e do contínuo aprimoramento do regime. Atenta às revoltas de 2013, a publicação articula passado e presente, memória e história, e aponta para os desafios da renovação, tanto no terreno da política quanto das interpretações acadêmicas, no que se refere à compreensão da dinâmica entre instituições governamentais, partidos e grupos sociais. 